RESEARCH ARTICLE - ANTS

\title{
Cryptic Lineages in the Cardiocondyla sl. kagutsuchi Terayama (Hymenoptera: Formicidae) Discovered by Phylogenetic and Morphological Approaches
}

\author{
I OKITA ${ }^{1}$, M TERAYAMA ${ }^{2}$, K TSUCHIDA $^{1}$ \\ 1 - Gifu University, Gifu, Japan \\ 2 - University of Tokyo, Tokyo, Japan
}

\author{
Article History

\section{Edited by} \\ Gilberto M. M. Santos, UEFS, Brazil \\ Received \\ 07 May 2015 \\ Initial acceptance \\ 22 July 2015 \\ Final acceptance \\ 04 August 2015

\section{Keywords} \\ Cardiocondyla, Mitochondrial DNA, \\ Morphology, Taxonomy.

\section{Corresponding author} \\ Ichiro Okita \\ The United Graduate School of \\ Agricultural Science \\ Gifu University, 1-1 Yanagido, Gifu, \\ 501-1193, Japan \\ E-Mail: okkie0626@yahoo.co.jp
}

\begin{abstract}
The taxonomy of ant species in the genus Cardiocondyla is very confused due to the extreme difficulty in separating many species based on morphology alone. In Japan, one group of the species complex Cardiocondyla sl. kagutsuchi has both winged and wingless worker-like (ergatoid) males (dimorphic) whereas others have only ergatoid males (monomorphic). The presence of both groups prompted us to hypothesize that $C$. sl. kagutsuchi presumably includes several independent species with differences in their male wing morphologies and modes of reproduction. However, whether any species boundary actually exists between the male groups has remained unsolved over the $10+$ years since the previous revision of this genus. In this study, using discriminant analysis, we compared the worker caste morphology of this species complex among lineages detected by phylogenetic analyses. In addition, we examined the number of sexuals present in field colonies. Our results revealed the existence of at least three morphological and phylogenetic groups within this species complex.
\end{abstract}

\section{Introduction}

Although most classic taxonomic techniques based on external morphology require a great deal of skill and are laborious, molecular markers based on DNA sequences have become a convenient and powerful genetic tool (Bickford et al., 2007) to unveil novel interspecific relationships, intraspecific variations, gene flow and adaptive mutations (Besansky et al., 2003; Molbo et al., 2003; Hebert et al., 2004; Murray et al., 2008; Cheng et al., 2011). Among such genetic concerns, detection of cryptic species can help us togain a deeper understanding of species interactions. In the field of myrmecology, this convenient tool has been used to detect several cryptic species among species complexes whose species status had been determined based mainly on external morphology (Schlick-Steiner et al., 2006; Ross et al., 2010; Yashiro et al., 2010; Bernasconi et al., 2011).

The ant genus Cardiocondyla (Formicidae: Myrmicinae), with approximately 70 described species (Bolton, 2014), displays male wing polymorphism (Bolton, 1982; Kugler, 1983; Seifert, 2003; Heinze et al., 2005; Oettler et al., 2010). Some species of this genus have both winged and wingless worker-like (ergatoid) males (dimorphic), while others have only ergatoid males (monomorphic). Winged males disperse from their natal nests using functional wings to seek mating partners when access to a virgin queen is unavailable within the nest. In contrast, ergatoid males stay in their natal nests and mate with virgin queens for the entirety of their lives (Kinomura \& Yamauchi, 1987; Yamauchi \& Kinomura, 1993; Heinze et al., 1998). The ergatoid males have well-developed mandibles and lifelong spermatogenesis. They engage in lethal fighting against other ergatoid rivals and monopolize virgin queens in their nests. In contrast, winged males are docile, have limited sperm supply, chemically mimic female sexuals and mate with virgin queens without being attacked by their wingless rivals (Kinomura \& Yamauchi, 1987; Yamauchi \& Kawase, 1992; Yamauchi \& Kinomura, 1993; Heinze et al., 1998; Cremer et al., 2002). Colonies of the male dimorphic 
species are polygynous and have only a single ergatoid male as the result of lethal fighting (Kinomura \& Yamauchi, 1987; Yamauchi \& Kinomura, 1993; Heinze et al., 1998; Boomsma et al., 2005). In colonies of male monomorphic Cardiocondyla species, this single ergatoid male system seems to be the rule also for some species (Oettler et al. 2010), whereas not for others: a polygynous species, Cardiocondyla mauritanica, sometimes contains more than one ergatoid male, which kill only callow rivals and do not engage in lethal fighting against full-grown rivals. Some monogynous species, e.g., Cardiocondyla batesii, Cardiocondyla elegans and Cardiocondyla ulianini, usually contain more than one ergatoid male which are mutually tolerant (Boomsma et al., 2005, Schrempf et al., 2005, Lenoir et al., 2007).

Cardiocondyla kagutsuchi sensu Seifert (2003), hereafter simply referred to as Cardiocondyla sl. kagutsuchi, is native to East and Southeast Asia, and has both monomorphic and dimorphic male groups (Seifert, 2003; Heinze et al., 2005; Yamauchi et al., 2005; Okita et al., 2013). The presence of both groups prompted us to hypothesize that $C$. sl. kagutsuchi presumably includes several independent species with differences in their male wing morphologies and modes of reproduction (Yamauchi et al., 2005; Seifert, 2008; Yamane, 2010). However, whether any species boundary actually exists between the male groups has remained unsolved over the $10+$ years since the previous revision of this genus (Seifert, 2003).

The male dimorphic group of $C$. sl. kagutsuchi is widely distributed from East Asia to South-East Asia, including Japan, whereas the male monomorphic group of the species occurs in Japan and Polynesian Islands including Hawaii (Yamauchi et al., 2005; Okita et al., 2013; Frohschammer and Heinze, 2009). The male monomorphic group in Japan has more than one ergatoid male, whereas the male dimorphic group in Japan has only a single ergatoid male (Yamauchi \& Kinomura, 1993). The two groups in Japan were originally thought to be two distinct species because of the differences in male morphology (Terayama, 1999), but were later considered to be a single species because of the high morphological similarity between the worker castes of the two groups (Seifert, 2003). However, our previous phylogenetic analyses showed that the two groups can be classified into distinct lineages (Okita et al., 2013). Furthermore, the monomorphic group consisted of at least two lineages, with one of the monomorphic lineages at a considerable genetic distance from the other, i.e., the substitution rate of mtDNA COI/II was 3.7\% (33bases/890, Okita et al., 2013). These phylogenetic analyses strongly suggest that worker caste morphology within the species complex $C$. sl. kagutsuchi should be compared among the lineages detected by phylogenetic analyses as well as between the male groups.

In this study, using additional samples of $C$. sl. kagutsuchi collected in Japan, we re-analysed the phylogenetic relationships and examined morphological differences in the worker caste among the lineages detected by phylogenetic analyses. In addition, we examined the number of sexuals (males and females) present in field colonies especially to reveal whether each male monomorphic lineage of $C$. sl. kagutsuchi in Japan has multiple males and/or females or not in a single colony.

\section{Materials and methods}

\section{Sample collection}

We collected colonies of C. sl. kagutsuchi in Honshu, Shikoku, Kyushu and the Ryukyus from early summer to late autumn (May-November). As Terayama (1999) reported that this ant inhabits open areas, we searched for colonies on the seashore, parks and vegetable fields. When colonies were found in the soil, we collected the whole colony by carefully digging up the soil using a scoop. When whole colonies were difficult to access (e.g., several colonies were found in the gaps between tiles and stones), we collected at least 10 workers from each colony at the colony entrances. In total, we studied specimens from 79 C. sl. kagutsuchi colonies, including one colony previously analysed by Heinze et al. (2005) and 20 from our previous study (Okita et al., 2013). Among the 79 colonies, 38 from 37 sites were collected from Honshu, Shikoku and Kyushu (temperate zone), 16 from 15 sites were from Okinawa Island (subtropical zone) and 25 from 18 sites were from Ishigaki and Iriomote islands (subtropical zone). Ants were preserved in $99.5 \%$ ethanol or brought live to our laboratory after field collection. We counted the numbers of sexuals (winged males, ergatoid males, winged females and wingless females) present in field colonies if applicable. For morphological analysis, we also examined paratype workers $(n=4)$ of $C$. sl. kagutsuchi, and nontype material of Cardiocondyla strigifrons Viehmeyer, 1922 (one colony). Note that the colony of $C$. strigifrons was collected by Dr. Yamauchi in Indonesia, and it was identified as C. strigifrons in Seifert (2003) and treated as C. strigifrons in previous phylogenetic analyses (Heinze et al., 2005; Okita et al., 2013).

\section{Phylogenetic analysis}

An 829-bp fragment of the COI/II regions deleting the tRNA leucine region between $\mathrm{COI}$ and COII was used for phylogenetic analysis. DNA was extracted from individual workers using Landry's method (Cheung et al., 1993). The dried DNA pellet was suspended with autoclaved distilled water $\left(\mathrm{DW}^{2}\right)$ and preserved at $-20^{\circ} \mathrm{C}$ until further analysis. We amplified COI/II using the primers C1-J-2195 and C2N-3661, respectively (Simon et al., 1994). Polymerase chain reaction (PCR) was performed in mixtures containing $2 \mu \mathrm{l}$ of template DNA suspended with $\mathrm{DW}^{2}, 0.55 \mu \mathrm{M}$ of each primer, 0.65 U of Ex Taq Hot Start Version (TaKaRa, Otsu, Shiga, Japan), 10× PCR Buffer (100 mM Tris-HCl, pH 8.3, 500 mM $\mathrm{KCl}, 15 \mathrm{mM} \mathrm{MgCl}_{2}$ ) and $0.25 \mathrm{mM}$ of each deoxynucleoside triphosphate in a Thermal Cycler (Dice ver. III TP600; 
TaKaRa). PCR consisted of an initial denaturation at $95^{\circ} \mathrm{C}$ for 4 minutes followed by 34 cycles of denaturation at $95^{\circ} \mathrm{C}$ for 1 minute, annealing at $59^{\circ} \mathrm{C}$ for 1 minute and extension at $72^{\circ} \mathrm{C}$ for 2 minutes. Amplified DNA was purified using a PCR Purification Kit (Qiagen, Hilden, Germany). All products were sequenced using a BigDye ${ }^{\mathrm{TM}}$ Terminator v 3.1 Cycle Sequencing Kit (Applied Biosystems, Foster City, CA, USA) and the primers C1-J-2195 (Simon et al., 1994) and 3F (Okita et al., 2013) designed as an internal primer between C1-J2195 and C2-N-3661 with the ABI PRISM 3100 (Applied Biosystems). Sequencing reactions consisted of one cycle of 1 minute at $96^{\circ} \mathrm{C}, 25$ cycles of $10 \mathrm{~s}$ at $96^{\circ} \mathrm{C}, 5 \mathrm{~s}$ at $50^{\circ} \mathrm{C}$ and 4 minutes at $60^{\circ} \mathrm{C}$, then stopped by cooling to $4^{\circ} \mathrm{C}$. We obtained sequences of all 79 colonies of $C$. sl. kagutsuchi from Japan, among which the sequences of 21 colonies had already been obtained in previous studies and consisted of only four haplotypes (Heinze et al., 2005; Okita et al., 2013; accession numbers: DQ023082, AB723724, AB723725, AB723726, AB723727; DQ023082 was the same haplotype as AB723724). For phylogenetic analysis, we obtained an additional 25 sequences (Heinze et al., 2005) from GenBank (accession numbers: AY754686, DQ023061, DQ023064, DQ023068, DQ023071, DQ023080, DQ023081, DQ023083, DQ023084, DQ023085, DQ023086, DQ023087, DQ023088, DQ023089, DQ023091, DQ023094, DQ023095, DQ023096, DQ023102, DQ023105, DQ023107, DQ023108, DQ023109, DQ023113, DQ023118). Eight of the 25 sequences were those of $C$. sl. kagutsuchi detected in Hawaii, Indonesia and Malaysia, and 15 sequences were those of other Cardiocondyla species, including Cardiocondyla atalanta, C. batesii, C. bulgarica, C. elegans, C. koshewnikovi, C. mauritanica, C. minutior, C. nigra, C. obscurior, C. parvinoda, C. stambuloffi, C. strigifrons, C. tjibodana, C. ulianini and C. wroughtonii. The other two sequences of Monomorium pharaonis and Harpagoxenus sublaevis were used as outgroups according to previous phylogenetic studies (Heinze, 2005; Moreau, 2006).

Phylogenetic relationships were inferred from the sequences aligned using CLUSTALW (Thompson et al., 1994) with distance, maximum likelihood and Bayesian methods. A neighbour-joining tree with Kimura 2-parameter distance method (Kimura, 1980) and a maximum likelihood tree applying a general time-reversible model with an invariable and a $\gamma$-distributed substitution rate $(\mathrm{GTR}+\mathrm{I}+\mathrm{G})$ model selected by Bayesian information criterion (BIC) scores were constructed using MEGA5.2 (Tamura et al., 2011), with bootstrap values estimated from 5000 replicates. Bayesian inference was performed using MrBayes ver. 3.2.2 (Ronquist et al., 2012) with the GTR $+\mathrm{I}+\mathrm{G}$ model selected by Akaike information criterion (AIC) scores in MrModeltest 2.3 (Nylander, 2004). Two runs with four chains of Markov chain Monte Carlo iterations were performed for 1,000,000 generations. Trees were kept every 100 generations, and the latest $75 \%$ of trees were used to calculate the $50 \%$ majorityrule trees and to determine the posterior probabilities.
Morphological analysis

We randomly selected five workers from each of the 79 colonies of $C$. sl. kagutsuchi originating in Japan and compared the worker morphologies of each lineage based on our phylogenetic analyses. We measured six body parts (Fig 1) of the workers, including the paratypes $(n=4)$ of $C$. sl. kagutsuchi, using a stereomicroscope (SZX7; Olympus, Tokyo, Japan) connected to a digital camera (DP21; Olympus) and digital imaging software (CellSens Standard; Olympus) or a scanning electron microscope (SEM; JSM-6610LA; JEOL, Tokyo, Japan). The measured parts were selected according to Seifert (2003). The following explanations of measured body parts are the same as those of Seifert (2003), with some minor modifications:

1. Head length (HL): maximum head length in the median line; excavation of the posterior margin of the head reduces the $\mathrm{HL}$.

2. Head width (HW): maximum head width including the eyes.

3. Metanotal groove (MGr): depth of the metanotal groove or depression in lateral view, measured from the tangent connecting the dorsalmost points of the promesonotum and propodeum.

4. Spine height $(\mathrm{SpH})$ : height of the propodeal spine in lateral view, measured from the tangent connecting the dorsalmost points of the propodeum and propodeal spine to the meniscus between the propodeum and propodeal spine.

5. Petiole length $(\mathrm{PeL})$ : diagonal maximum length of the petiole in lateral view, measured from the anterior corner of the subpetiolar process to the posterodorsal corner of the petiole.

6. Petiole height $(\mathrm{PeH})$ : maximum petiole node height.
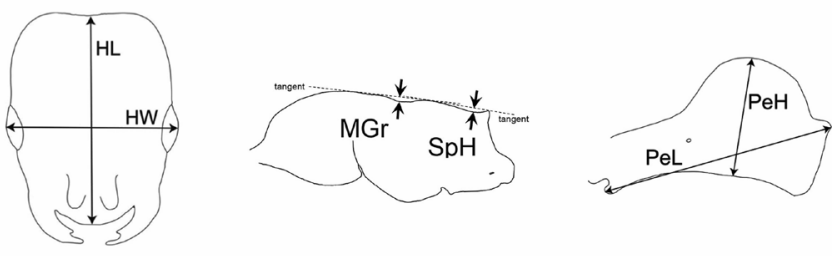

Fig 1. Six measured parts (HL, HW, MGr, SpH, PeL, PeH) of Cardiocondyla sl. kagutsuchi workers for morphological analysis. These figures were drawn from the SEM photographs of the specimens. The left figure represents a dorsal view of the head, the middle shows a lateral view of the mesosoma and that on the right is a lateral view of the petiole. HL, HW, MGr, $\mathrm{SpH}, \mathrm{PeL}$ and $\mathrm{PeH}$ represent the head length, head width, depth of the metanotal groove, height of the propodeal spine, petiole length and petiole height, respectively.

Following the measurements, canonical discriminant analysis (DA) was performed using SPSS v. 22 (SPSS Inc., Chicago, IL, USA) to determine whether the mtDNA lineages would be compatible with differences in the external morphology of the workers. Using a stepwise method, we selected characteristic measurements that minimized the overall Wilk's $\lambda$ and used them for the DA. After running "Leave-One-Out Cross-Validation" analysis, we examined the compatibilities 
between mtDNA lineages and external morphology. In cases in which compatibility was detected, we applied the obtained discriminant functions to the morphological data on paratype workers $(n=4)$ of $C$. kagutsuchi and determined whether the paratypes could be classified to one of the lineages. Furthermore, our previous phylogenetic study (Okita et al., 2013) showed that the genetically closest species to $C$. sl. kagutsuchi was C. strigifrons, which was distinguished from $C$. sl. kagutsuchi by the dorsal mesosomal sculpture of the worker caste (Seifert, 2003). Therefore, in this study, we randomly selected one worker from each colony of the lineage that was genetically closest to $C$. strigifrons, as well as five workers from the colony of $C$. strigifrons, and examined whether the selected workers of $C$. sl. kagutsuchi could be distinguished from these five workers of $C$. strigifrons based on the dorsal mesosomal sculpture using a stereomicroscope or SEM. The ratio of "Head length" to "Head width" (HL/ HW) of C. strigifrons workers is known to be larger than that of C. sl. kagutsuchi (Seifert, 2003). Therefore, we examined the significance of differences between the mean HL/HW value of the selected five workers of $C$. strigifrons and that of all measured workers of the lineage genetically closest to $C$. strigifrons by the $t$ test.

\section{Results}

\section{Phylogenetic analyses and lineage distribution}

In previous studies (Heinze et al., 2005; Okita et al., 2013), four haplotype sequences in the mtDNA COI/II regions were detected in C. sl. kagutsuchi from Japan. In this study, we obtained the same four haplotypes in 79 colonies of $C$. sl. kagutsuchi from Japan, including 58 newly collected colonies. That is, no new haplotypes were detected in this study. Briefly, C. sl. kagutsuchi from Japan was divided into four lineages (A, B, C and D), which corresponded to haplotypes 1, 3, 4 and 2, respectively, in Okita et al. (2013), with accession numbers AB723724, AB723726, AB723727 and AB723725 (Figs 2, 3). In the phylogenetic trees, $C$. sl. kagutsuchi was divided into two distinct clades; one clade included lineages $\mathrm{A}, \mathrm{B}$ and $\mathrm{C}$, and the other included lineage $\mathrm{D}$. The former clade was further divided into two subclades; one subclade included lineages A and B, and the other included lineage $C$. These results suggested that C. sl. kagutsuchi in Japan was likely divided into three genetic groups: the first consisting of lineages A and B, the second of $\mathrm{C}$ and the third of D. Based on these analyses, lineage D was genetically distant from the others. In fact, the substitution rates

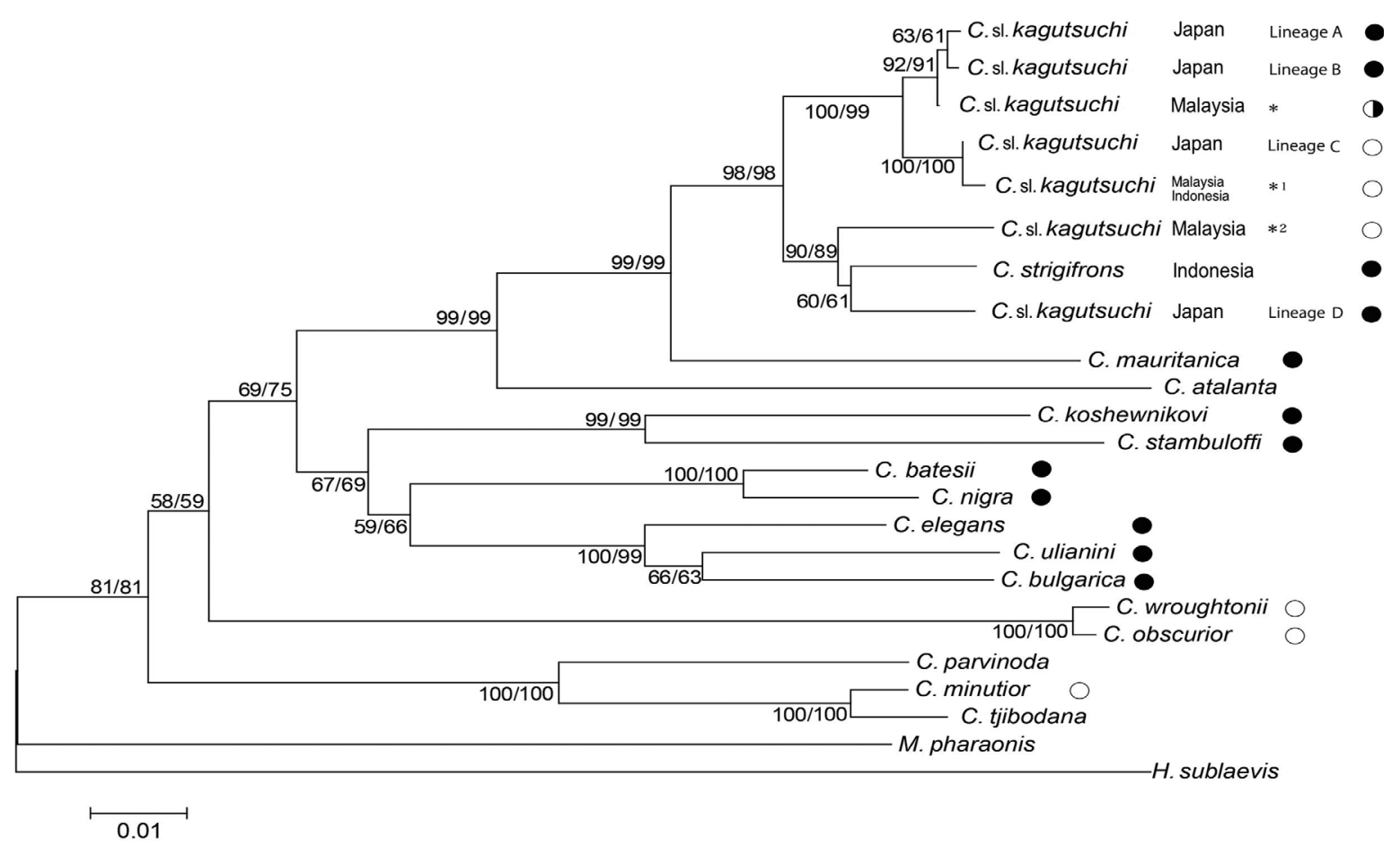

Fig 2. Neighbour-joining tree based on the mitochondrial COI/II genes ( $829 \mathrm{bp}$ ) of the ant genus Cardiocondyla and two other genera. Bootstrap support values in 5,000 pseudoreplicates for distance and likelihood analyses are shown by the left and right numbers at the node, respectively. The genera names are as follows: $C$-Cardiocondyla, $M-$ Monomorium and H-Harpagoxenus. Geographic origins of $C$. sl. kagutsuchi and $C$. strigifrons are shown following their species names. Accession numbers of Lineages A, B, C and D of C. sl. kagutsuchi were AB723724, AB723726, AB723727 and AB723725, respectively. Lineage D was the same haplotype as DQ023088 (Hawaii). Accession numbers of other lineages of C. sl. kagutsuchi were as follows (*: DQ023083 and DQ023084, *1: DQ023081, DQ023085, DQ023086 and DQ023087. *2: DQ023080). White circles indicate that both winged and ergatoid males were present, half-white and half-filled circles represent both short-winged and ergatoid males and filled circles denote ergatoid males only (Heinze et al., 2005; Yamauchi et al., 2006; Okita et al., 2013). Male morphology of lineage B was based on Okita's personal observations. No males were found for C. atalanta, C. parvinoda and C. tjibodana. The number of colonies and sampling sites of each of the four $C$. sl. kagutsuchi lineages in Japan are as follows: lineage A, 33 colonies in 32 sites; lineage B, 15 colonies in 14 sites; lineage C, 10 colonies in 3 sites; lineage D, 21 colonies in 21 sites (Fig 4). 


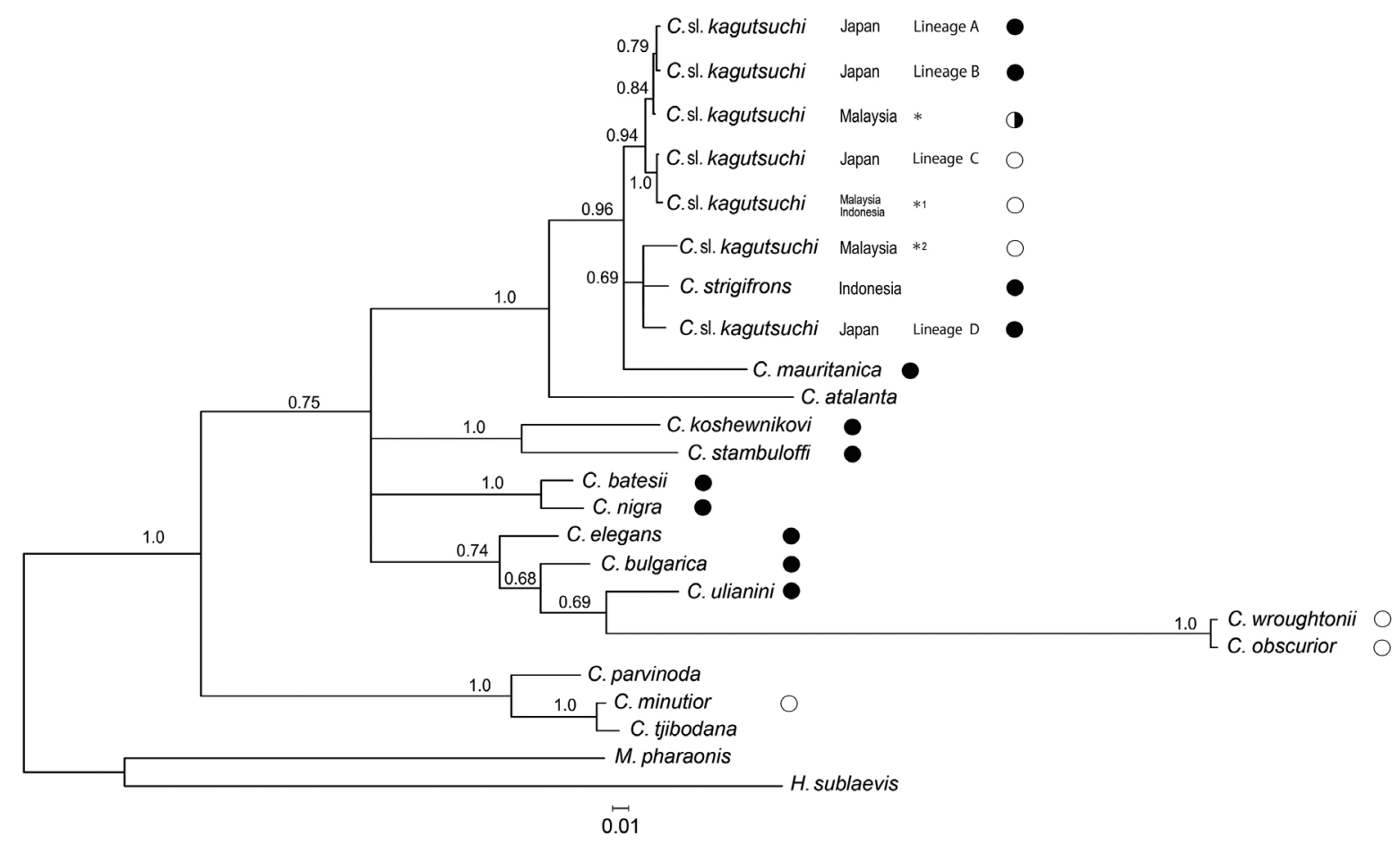

Fig 3. Majority rule consensus tree based on the mitochondrial COI/II genes ( $829 \mathrm{bp}$ ) of the ant genus Cardiocondyla and two other genera from Bayesian analysis (1,000,000 generations). The posterior probabilities are shown at the node. The genera names are as follows: $C$-Cardiocondyla, M-Monomorium and H-Harpagoxenus. Geographic origins of $C$. sl. kagutsuchi and $C$. strigifrons are shown following their species names. Accession numbers of Lineages A, B, C and D of C. sl. kagutsuchi were AB723724, AB723726, AB723727 and AB723725, respectively. Lineage D was the same haplotype as DQ023088 (Hawaii). Accession numbers of other lineages of C. sl. kagutsuchi were as follows (*: DQ023083 and DQ023084, *1: DQ023081, DQ023085, DQ023086 and DQ023087. *2: DQ023080). White circles indicate that both winged and ergatoid males were present, half-white and half-filled circles show both short-winged and ergatoid males and filled circles denote ergatoid males (Heinze et al., 2005; Yamauchi et al., 2006; Okita et al., 2013). Male morphology of lineage B was based on Okita's personal observations. No males were found for C. atalanta, C. parvinoda and C. tjibodana. The number of colonies and sampling sites of four C. sl. kagutsuchi lineages in Japan were as follows: lineage A, 33 colonies in 32 sites; lineage B, 15 colonies in 14 sites; lineage C, 10 colonies in 3 sites; lineage D, 21 colonies in 21 sites (Fig 4).

between lineage $\mathrm{D}$ and the other three $(>3.5 \%$; Table 1$)$ were higher than those of three Cardiocondyla species pairs, i.e., $0.6 \%$ between $C$. obscurior and C. wroughtonii, $1.6 \%$ between C. minutior and C. tjibodana, and $3.1 \%$ between C. batesii and C. nigra. Furthermore, the substitution rates between lineage $\mathrm{D}$ and the other three were higher than those between lineage D and C. strigifrons (2.6\%; Table 1).

Table 1. Substitution rates (\%) of mtDNA COI/II regions (829 bp) among four mtDNA lineages (A, B, C and D; Figs 2 and 3) of Cardiocondyla sl. kagutsuchi in Japan and Cardiocondyla strigifrons.

\begin{tabular}{cccccc}
\hline & & $\mathrm{A}$ & $\mathrm{B}$ & $\mathrm{C}$ & C. strigifrons \\
\hline \multirow{5}{*}{ C. kagutsuchi $i$} & $\mathrm{~A}$ & - & - & - & 4.0 \\
& $\mathrm{~B}$ & 0.2 & - & - & 3.7 \\
& $\mathrm{C}$ & 1.2 & 1.2 & - & 3.7 \\
& $\mathrm{D}$ & 3.9 & 3.6 & 3.9 & 2.6 \\
\hline
\end{tabular}

Lineages $\mathrm{A}$ and $\mathrm{D}$ were distributed widely in the temperate and subtropical zones of Japan from Honshu (main island) to Ishigaki and Iriomote islands, lineage B was distributed in the subtropical zone of Japan from Okinawa Island to Ishigaki and Iriomote islands and lineage $\mathrm{C}$ was distributed only in the subtropical zone of Japan on Ishigaki Island (Fig 4).

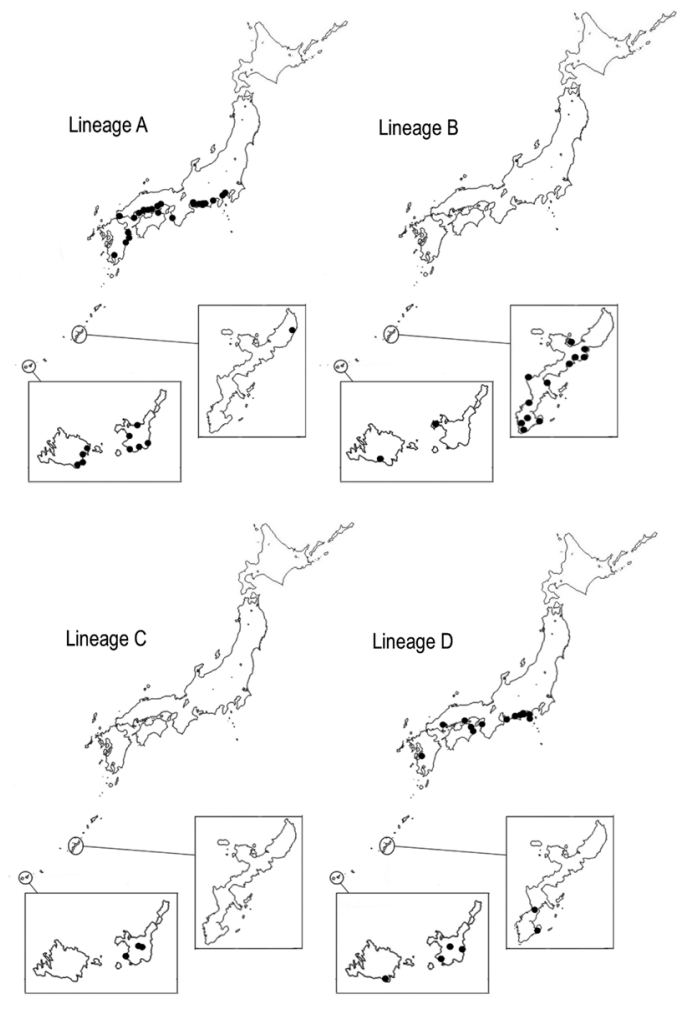

Fig 4. Distribution map of Cardiocondyla sl. kagutsuchi lineages A, $\mathrm{B}, \mathrm{C}$ and D in Japan. 
Table 2. Metric traits (mean $\pm \mathrm{SE}, \mu \mathrm{m}$ ) of six measured parts (Fig 1) obtained from the four mtDNA lineages (A, B, C and D) of Cardiocondyla sl. kagutsuchi workers in Japan. HL, HW, MGr, SpH, PeL and PeH designate the head length, head width, depth of the metanotal groove, height of the propodeal spine, petiole length and petiole height, respectively.

\begin{tabular}{cccccccc}
\hline Lineage & HL & HW & MGr & SpH & PeL & PeH \\
\hline A & $556.6 \pm 2.0$ & $465.1 \pm 1.4$ & $8.0 \pm 0.2$ & $4.7 \pm 0.1$ & $303.7 \pm 1.3$ & $157.3 \pm 0.7$ \\
B & $563.3 \pm 2.7$ & $467.0 \pm 2.2$ & $7.8 \pm 0.2$ & $4.8 \pm 0.2$ & $306.5 \pm 1.5$ & $158.9 \pm 0.8$ \\
C & $563.6 \pm 3.2$ & $472.1 \pm 2.7$ & $9.1 \pm 0.4$ & $7.8 \pm 0.3$ & $308.0 \pm 2.4$ & $149.5 \pm 1.2$ \\
D & $566.8 \pm 2.2$ & $482.7 \pm 1.9$ & $12.0 \pm 0.3$ & $10.2 \pm 0.2$ & $308.2 \pm 1.5$ & $165.0 \pm 0.8$ \\
\hline
\end{tabular}

\section{Morphological analyses}

Phylogenetic analyses (Figs 2,3) showed that C. sl. kagutsuchi in Japan was clearly divided into four lineages. Therefore, we measured and analysed six body parts (Fig 1) of workers of the following samples: lineage A, 165 workers ( 33 colonies) in 32 sites; lineage B, 75 workers ( 15 colonies) in 14 sites; lineage $\mathrm{C}, 50$ workers ( 10 colonies) in 3 sites; lineage D, 105 workers (21 colonies) in 21 sites (Fig 4). These data are available from the Online Supplementary Material. The means $\pm \mathrm{SE}(\mu \mathrm{m})$ of the six measurements (Fig 1) of the four lineages are shown in Table 2.

Table 3. Classification of predicted lineage for lineages A, B, C and $\mathrm{D}$ of Cardiocondyla sl. kagutsuchi workers in Japan using discriminant analysis (DA). Numerical values are the number of individuals that DA classified into each of the four lineages.

\begin{tabular}{cccccc}
\hline \multirow{2}{*}{ Lineage } & \multicolumn{5}{c}{ Predicted lineage } \\
\cline { 2 - 6 } & A & B & C & D & Total correct (\%) \\
\hline A & 70 & 76 & 9 & 10 & $70 / 165(42.4)$ \\
B & 38 & 30 & 6 & 1 & $30 / 75(40.0)$ \\
C & 3 & 1 & 45 & 1 & $45 / 50(90.0)$ \\
D & 0 & 3 & 0 & 102 & $102 / 105(97.1)$ \\
\hline
\end{tabular}

Selected characteristic measurements using a stepwise method in the DA included $\mathrm{SpH}, \mathrm{PeH}, \mathrm{PeL}$ and $\mathrm{MGr}$ in order of selection, and these characteristic measurements contributed significantly to the discrimination (Wilk's $\lambda=0.169$, $\left.F_{12,102.843}=81.993, P<0.001\right)$. The rate of individual workers correctly assigned to lineage A by the DA was $42.4 \%$, that of lineage B was $40.0 \%$, that of lineage $C$ was $90.0 \%$ and that of lineage D was $97.1 \%$ (Table 3 ). These rates showed that our DA correctly discriminated each of lineages $\mathrm{C}$ and $\mathrm{D}$ from theother three lineages, whereas they failed to discriminate between lineages A and B (Table 3). Two canonical discriminant functions that significantly discriminated between the lineages were obtained: the first function (Wilk's $\lambda=0.169$, d.f. $=12, \chi^{2}=693.422, P<0.001$ was $+0.175 \times \mathrm{MGr}+0.104 \times \mathrm{PeH}-0.062 \times \mathrm{PeL}-1.731$, and the secondfunction (Wilk's $\lambda=0.547$, d.f. $=6, \chi^{2}=235.308, P<0.001$ ) was $+0.080 \times \mathrm{MGr}-0.207 \times \mathrm{PeH}+0.086 \times \mathrm{PeL}+4.238$. The first function explained $73.1 \%$ of the variance, while the second function explained $26.6 \%$.

The average discriminant scores of each lineage (Table 4) showed that the first function discriminated lineage $D$ and the second function discriminated lineage C. Using the first and second functions, the discriminant scores of all individual workers are plotted in Fig 5.

Briefly, our DA showed that $C$. sl. kagutsuchi, distributed from Honshu to Ishigaki and Iriomote islands, consisted of three morphological groups compatible with the mtDNA lineages: lineages A and B could be compiled as the first group, lineage $\mathrm{C}$ as the second group and lineage $\mathrm{D}$ as the third group (Fig 5). The standardized discriminant function coefficients (Table 5) showed that the third group (lineage D) had larger $\mathrm{SpH}, \mathrm{PeH}$ and MGr and smaller PeL than the other two groups, and the second group (lineage $\mathrm{C}$ ) had a larger PeL and smaller $\mathrm{PeH}$ than the other two groups with regard to worker morphology. SEM photographs (Fig 6) show these morphological characteristics in the three groups. In addition, we applied the obtained discriminant functions to the morphological data on worker paratypes $(n=4$; data are available from the Online Supplementary Material) of $C$. sl. kagutsuchi, and all of these paratypes were assigned to the second group (lineage C; Fig 5) with high probabilities $(0.963,0.935,0.911,0.996)$.

Table 4. Discriminant scores (mean \pm SE) of each lineage (A, B, C and D) of Cardiocondyla sl. kagutsuchi in Japan. A plus or minus sign on the discriminant score of each lineage shows that the first function discriminates lineage $\mathrm{D}$ and the second function discriminates lineage $\mathrm{C}$.

\begin{tabular}{ccc}
\hline \multirow{2}{*}{ Lineage } & \multicolumn{2}{c}{ Function } \\
\cline { 2 - 3 } & 1 & 2 \\
\hline A & $-0.924 \pm 0.080$ & $-0.572 \pm 0.072$ \\
B & $-0.924 \pm 0.111$ & $-0.657 \pm 0.124$ \\
C & $-0.543 \pm 0.108$ & $+2.165 \pm 0.117$ \\
D & $+2.495 \pm 0.105$ & $-0.294 \pm 0.109$ \\
\hline
\end{tabular}

Table 5. Standardized coefficients of the two discriminant functions. The first function discriminates lineage $\mathrm{D}$ and the second function discriminates lineage $\mathrm{C}$ of Cardiocondyla sl. kagutsuchi in Japan (Table 4). SpH, MGr, PeH and PeL designate the height of the propodeal spine, depth of the metanotal groove, petiole height and petiole length, respectively.

\begin{tabular}{ccc}
\hline & \multicolumn{2}{c}{ Function } \\
\cline { 2 - 3 } & 1 & \multicolumn{1}{c}{2} \\
\hline $\mathrm{SpH}$ & 0.806 & 0.424 \\
$\mathrm{MGr}$ & 0.425 & 0.195 \\
$\mathrm{PeH}$ & 0.852 & -1.688 \\
$\mathrm{PeL}$ & -0.970 & 1.346 \\
\hline
\end{tabular}


Our phylogenetic studies showed that the lineage genetically closest to $C$. strigifrons was lineage $\mathrm{D}$ (Table 1, Figs 2,3 ), and we examined whether lineage D was morphologically distinguishable from C. strigifrons. Visual inspection of the deviating dorsal mesosomal sculpture (a morphological criterion used by Seifert (2003) to separate $C$. strigifrons from C. kagutsuchi) of lineage $\mathrm{D}$ and $C$. strigifrons revealed that all workers of lineage $\mathrm{D}$ examined could be clearly discriminated from C. strigifrons; the circular sculptures (foveolae) of the dorsal promesonotum of $C$. strigifrons were apparently shallower than in lineage D. Furthermore, the number of sculptures of $C$. strigifrons was considerably less than that of lineage D (Fig 7). The mean value of HL/HW for all measured workers of lineage $\mathrm{D}$ (mean $\pm \mathrm{SE}, 1.175 \pm 0.002, n=105$ ) was significantly different from that of $C$. strigifrons $(1.274 \pm 0.010$, $n=5 ; t_{\text {cal }}=-10.13$, d.f. $=108, P<0.001$; morphological data are available from the Online Supplementary Material).

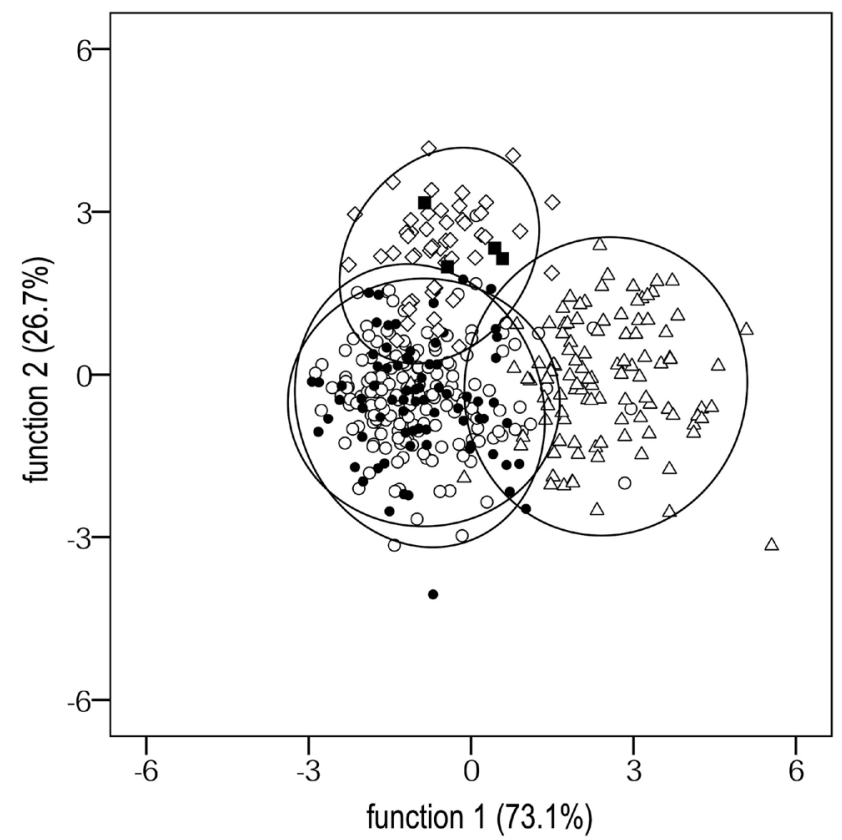

Fig 5. Scatter plot of the discriminant scores of individual workers of Cardiocondyla sl. kagutsuchi in Japan using the first and second functions: lineage A (open circle, $n=165$ workers), lineage B (filled circle, $n=75$ workers), lineage $\mathrm{C}$ (diamond, $n=50$ workers), lineage D (triangle, $n=105$ workers) and paratypes (filled square, $n=4$ workers). Ellipses are $95 \%$ confidence limit lines.

\section{Number of sexuals per colony}

We obtained a total of 24 colonies containing sexuals; seven colonies were from lineage $\mathrm{A}$, one colony was from lineage $\mathrm{B}$, eight colonies were from lineage $\mathrm{C}$ and nine were from lineage D (Table 6). Among these 24 colonies, four contained no female sexuals, probably due to incomplete sample collection. Irrespective of incomplete sample collection, our data (Table 6) showed that nearly half of the colonies from lineages $\mathrm{A}$ and $\mathrm{D}$ contained more than one ergatoid male (lineage A: 3/7, lineage D: 4/9) and wingless females (lineage A: 5/7, lineage D: 6/9).
With regard to male morphology, our previous study (Okita et al., 2013) showed that lineages A and D were monomorphic (only ergatoid males) and lineage $\mathrm{C}$ was dimorphic (winged and ergatoid males). The results of this study (Table 6) agreed with those reported previously. We obtained only one colony containing sexuals in lineage B. This colony produced several ergatoid males and no winged males for more than 1.5 years under laboratory conditions (Okita, personal observation).
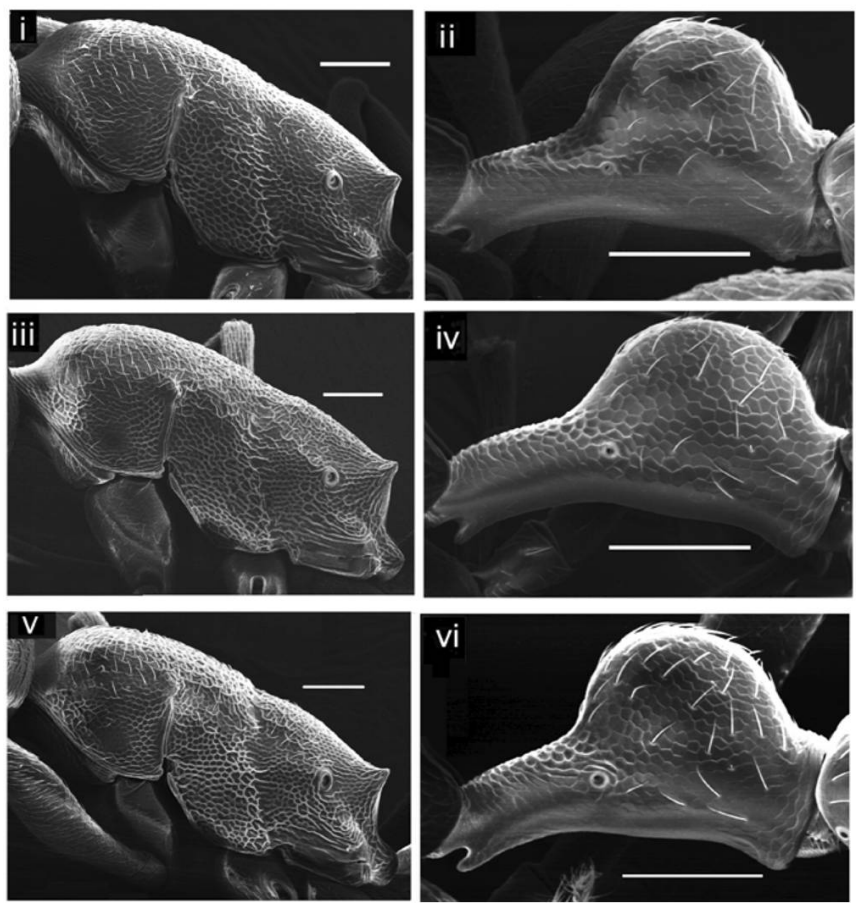

Fig 6. SEM images of the workers of group consisting of lineages A and B ( $\mathrm{i}$ and ii) of Cardiocondyla sl. kagutsuchi, those of lineage C (iii and iv) and those of lineage D (v and vi). Pictures on the left display a lateral view of the mesosoma and pictures on the right show a lateral view of the petiole. Each scale bar is $100 \mu \mathrm{m}$.

\section{Discussion}

This study showed that C. sl. kagutsuchi in Japan consisted of three groups that differed in both mtDNA sequences and worker morphology: lineages $\mathrm{A}+\mathrm{B}, \mathrm{C}$ and $\mathrm{D}$.

Originally, C. kagutsuchi Terayama, 1999 was the species name given to the endemic ant collected from Ishigaki Island known to have both winged and ergatoid males (Terayama, 1999). With regard to the distribution area and male morphology of our samples, lineage $C$ has so far been collected only from Ishigaki Island (Fig 4), and most of the examined colonies $(6 / 8)$ contain winged males or both winged and ergatoid males (Table 6) as mentioned by Terayama (1999). Furthermore, our DAs showed that all paratypes of worker $C$. kagutsuchi $(n=4)$ were assigned to lineage C (Fig 5) with high probabilities $(0.963,0.935,0.911,0.996)$. Thus, lineage C is likely assigned to C. kagutsuchi Terayama,1999 for the following three reasons: i) a high morphological similarity 
between lineage $\mathrm{C}$ and the paratype of C. kagutsuchi; ii) the presence of male dimorphism in lineage $\mathrm{C}$ as mentioned by Terayama (1999); and iii) an overlapping distribution between lineage $\mathrm{C}$ and the paratypes. The substitution rates between the group of lineage $\mathrm{D}$ and the other two groups consisting of lineages $\mathrm{A}+\mathrm{B}$ and $\mathrm{C}$ were more than $3.5 \%$ (Table 1), which was higher than those of three Cardiocondyla species pairs (Figs 2, 3). Schlick-Steiner et al. (2006) considered certain lineages of Tetramorium ants in Europe as new species, in which the interspecific substitution rates of the mtDNA COI region were between $1.6 \%$ and $8.5 \%$. The observed substitution rates between the group of lineage $\mathrm{D}$ and the other two groups consisting of lineages $\mathrm{A}+\mathrm{B}$ and $\mathrm{C}(>3.5 \%$, Table 1) showed a fair amount of overlap with the interspecific substitution rates of the European Tetramorium ant species pairs (between 1.6\% and $8.5 \%$ ), suggesting that lineage $\mathrm{D}$ is a distinct species from the other two groups. Furthermore, with regard to morphology,

Table 6. Number of sexuals present in 24 field colonies of Cardiocondyla sl. kagutsuchi in Japan. We counted the number only if collected colonies contained sexuals. Four colonies did not have any female sexuals, possibly due to incomplete sample collection.

\begin{tabular}{|c|c|c|c|c|c|}
\hline \multirow{3}{*}{ Lineage } & \multicolumn{4}{|c|}{ Number of } & \multirow{3}{*}{$\begin{array}{l}\text { Month of } \\
\text { collection }\end{array}$} \\
\hline & \multicolumn{2}{|c|}{ male sexuals } & \multicolumn{2}{|c|}{ female sexuals } & \\
\hline & winged & ergatoid & winged & wingless & \\
\hline \multirow{7}{*}{ A } & 0 & 0 & 0 & 2 & May \\
\hline & 0 & 0 & 1 & 0 & July \\
\hline & 0 & 3 & 0 & 0 & July \\
\hline & 0 & 2 & 13 & 19 & August \\
\hline & 0 & 1 & 1 & 3 & September \\
\hline & 0 & 1 & 3 & 5 & November \\
\hline & 0 & 4 & 5 & 4 & November \\
\hline B & 0 & 2 & 0 & 1 & June \\
\hline \multirow{8}{*}{$\mathrm{C}$} & 2 & 1 & 2 & 0 & May \\
\hline & 1 & 0 & 0 & 1 & June \\
\hline & 1 & 0 & 0 & 1 & June \\
\hline & 1 & 0 & 0 & 0 & June \\
\hline & 1 & 0 & 0 & 0 & June \\
\hline & 0 & 0 & 1 & 13 & June \\
\hline & 0 & 0 & 0 & 1 & June \\
\hline & 1 & 1 & 3 & 1 & June \\
\hline \multirow{9}{*}{$\mathrm{D}$} & 0 & 3 & 0 & 1 & June \\
\hline & 0 & 2 & 3 & 0 & June \\
\hline & 0 & 1 & 14 & 4 & August \\
\hline & 0 & 1 & 0 & 0 & August \\
\hline & 0 & 3 & 22 & 9 & August \\
\hline & 0 & 6 & 65 & 58 & September \\
\hline & 0 & 0 & 4 & 7 & September \\
\hline & 0 & 0 & 2 & 4 & September \\
\hline & 0 & 1 & 1 & 2 & October \\
\hline
\end{tabular}

$97.1 \%$ of the workers in lineage D were correctly assigned to the same lineage by the DA (Table 3). This morphological analysis strongly suggested that lineage $\mathrm{D}$ is a distinct species. As the previous revision of this genus (Seifert, 2003) showed that $C$. strigifrons, which was genetically the closest species to lineage $\mathrm{D}$ (Figs 2, 3), was distinguished from C. sl. kagutsuchi by the dorsal mesosomal sculpture and head shape of the worker caste, we easily distinguished lineage $\mathrm{D}$ from $C$. strigifrons lineages based on sculpture (Fig 7) and the head shape of workers. Furthermore, the rate of mtDNA substitution between $C$. strigifrons and lineage $\mathrm{D}(2.6 \%)$ was higher than those of the two Cardiocondyla species pairs $(0.6 \%$ between $C$. obscurior and $C$. wroughtonii, $1.6 \%$ between C. minutior and C. tjibodana), and the lower extreme of those of the European Tetramorium ant species pair (1.6\%; Schlick-Steiner et al., 2006). These evidences strongly suggest that lineage $\mathrm{D}$ is a distinct species from $C$. strigifrons.
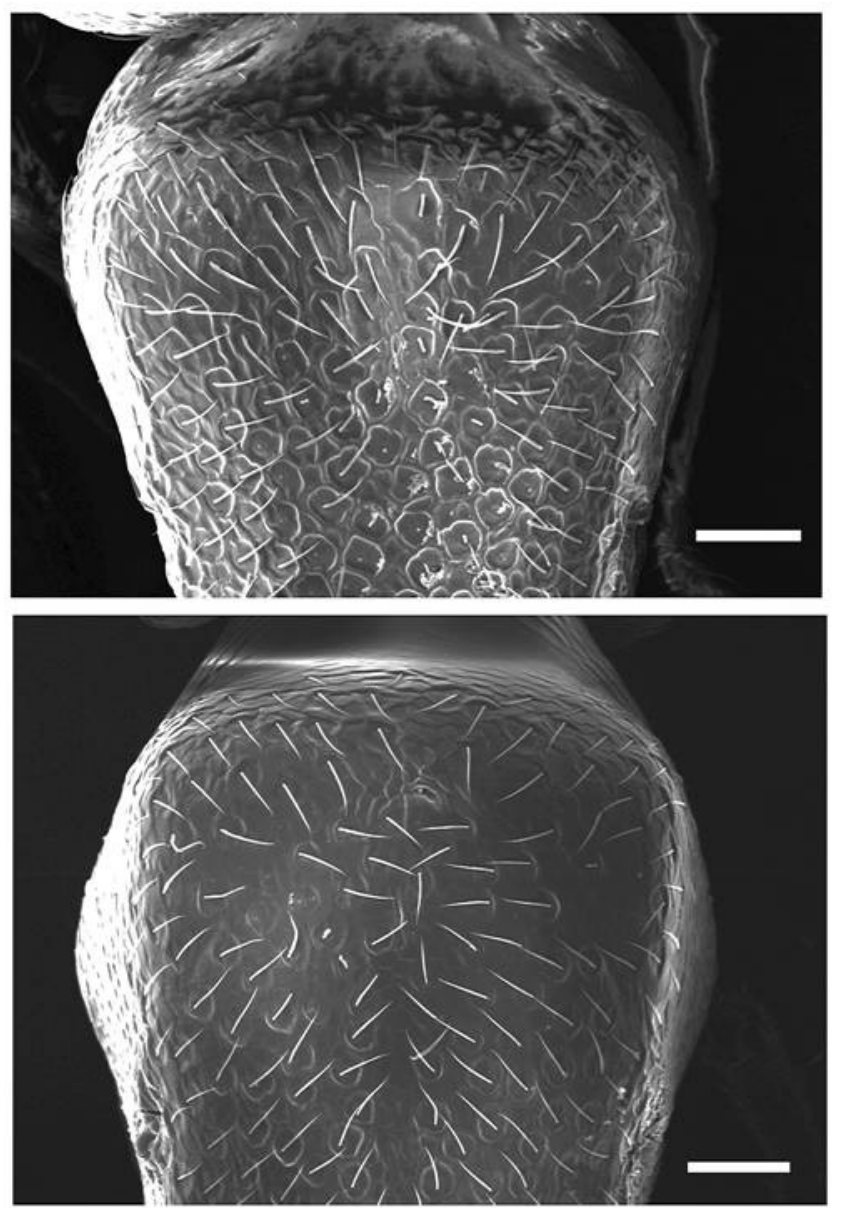

Fig 7. SEM images of the dorsal promesonotum of the worker caste. The top is lineage D of Cardiocondyla sl. kagutsuchi and the bottom is Cardiocondyla strigifrons. Each scale bar is $50 \mu \mathrm{m}$.

In this study, we showed that three phylogenetic and morphological groups (lineages $\mathrm{A}+\mathrm{B}, \mathrm{C}$ and $\mathrm{D}$ ) exist within C. sl. kagutsuchi in Japan. Furthermore, our previous study (Okita et al., 2013) showed that lineages A and D were male monomorphic, while lineage $\mathrm{C}$ was dimorphic. That is, male monomorphic C. sl. kagutsuchi in Japan includes at least two lineages differing in worker morphology. 
The previous revision of $C$. sl. kagutsuchi (Seifert, 2003) only examined morphological differences in the worker caste between two male groups (monomorphic vs. dimorphic) in Japan, and treated the two male groups as a single species because of the high morphological similarity between them. Our study, however, strongly suggests that $C$. sl. kagutsuchi is a species complex consisting of more than one species which are discriminated from each other by several independent approaches such as CO1-based phylogenetic analysis, comparative morphology, morphometry, and observation of reproductive system, and highlights the need for reclassification of this species complex. Further morphological analyses using C. sl. kagutsuchi samples from countries other than Japan and other related species samples along with genetic analyses of nuclear DNA will shed light on this species complex.

Finally, in some male monomorphic (only ergatoid) species of Cardiocondyla, monogynous species such as $C$. batesii, C. elegans and C. ulianini produce mutually tolerant ergatoid males in a single colony, whereas polygynous species such as $C$. mauritanica produce more than one ergatoid male in a single colony in which those males kill only callow rivals (Boomsma et al., 2005; Schrempf et al., 2005; Lenoir et al., 2007). In this study, the colonies of lineages $A$ and D (male monomorphism) frequently contained more than one ergatoid male and multiple wingless females in a single colony (Table 6). These observations suggest that the two lineages are not strictly monogynous and that the ergatoid males in lineages A and/or D are likely tolerant of each other, or may kill only callow rivals, similar to C. mauritanica. Another possibility is the presence of reproductive skew among nestmate queens in lineages A and/or D as reported in Cardiocondyla sp. by Yamauchi et al. (2007), whereby a single queen likely monopolizes the production of ergatoid males in each colony. Further studies are required to examine to what extent each ergatoid is tolerant as well as the ability of each queen to monopolize reproduction in each colony of C. sl. kagutsuchi lineages A and D.

\section{Acknowledgements}

We thank the staff of the Comprehensive Education Centre of Shizuoka Prefecture for allowing us to use their SEM facility. We thank Dr. Katsusuke Yamauchi for allowing us to inspect his ant collection, including C. strigifrons collected in Indonesia. We thank Mr. Kyoichi Kinomura for his assistance in collecting on Ishigaki Island. We thank Mr. Akihiro Hosoda and Drs. Keiichi Masuko, Tadao Matsumoto and Kaori Murase for their helpful advice from the beginning of our study. We thank Drs. Sadaharu Morinaka, Seiki Yamane and Katsuyuki Eguchi for their advice on collecting ants. We thank Ms. Michie Fukumoto for allowing us to collect ants in Takeda Botanical Garden on Ishigaki Island. We thank Mr. Felix Cowie and the staff of the Sancho-Jidosha-Shokai for their assistance. We also thank Drs. Masaki Okuno, Yusuke Kondo, Kazuhisa Yamasaki and Kakeru Yokoi for their kind support on our study.

\section{Supplementary Material}

Data set available at:

http://periodicos.uefs.br/ojs/index.php/sociobiology/rt/ suppFiles $/ 805 / 0$

DOI: 10.13102/sociobiology.v62i3.805.s902

\section{References}

Bernasconi, C., Cherix, D., Seifert, B. \& Pamilo, P. (2011). Molecular taxonomy of the Formica rufa group (red wood ants) (Hymenoptera: Formicidae): a new cryptic species in the Swiss Alps? Myrmecological News, 14: 37-47.

Besansky, N., Krzywinski, J., Lehmann, T., Simard, F., Kern, M., Mukabayire, O., Fontenille, D., Toure, Y. \& N'F, S. (2003). Semipermeable species boundaries between Anopheles gambiae and Anopheles arabiensis: evidence from multilocus DNA sequence variation. Proceedings of the National Academy of Sciences USA, 100: 10818-10823. doi:10.1073/pnas.1434337100.

Bickford, D., Lohman, D.J., Sodhi, N.S., Ng, P.K.L., Meier, R., Winker, K., Ingram, K.K. \& Das, I. (2007). Cryptic species as a window on diversity and conservation. Trends in Ecology and Evolution, 22: 148-155. doi:10.1016/j.tree.2006.11.004

Bolton, B. (1982). Afrotropical species of the Myrmicinae ant genera Cardiocondyla, Leptothorax, Melissotarsus, Messor and Cataulacus (Formicidae). Bulletin of the British Museum of Natural History (Ent.), 45: 307-370.

Bolton, B. (2014). An online catalog of the ants of the world. Available from http://antcat.org. (accessed [02.vi.2015])

Boomsma, J.J., Baer, B.C. \& Heinze, J. (2005). The evolution of male traits in social insects. Annual Review of Entomology, 50: 395-420. doi:10.1146/annurev.ento.50.071803.130416

Cheng, S., Kirton, L.G., Panandam, J.M., Siraj, S.S., Ng, K.K.S. \& Tan, S.G. (2011). Evidence for a higher number of species of Odontotermes (Isoptera) than currently known from Peninsular Malaysia from mitochondrial DNA phylogenies. PLoS ONE 6: e20992. doi:10.1371/journal.pone.0020992

Cheung, W., Hubert, N. \& Landry, B. (1993). A simple and rapid DNA microextraction method for plant, animal, and insect suitable for RAPD and other PCR analyses. Genome Research, 3: 69-70.

Cremer, S., Sledge, M. \& Heinze, J. (2002). Chemical mimicry: Male ants disguised by the queens' bouquet. Nature 419: 897. doi:10.1038/419897a

Frohchammer, S. \& Heinze, J. (2009). A heritable component in sex ratio and caste determination in a Cardiocondyla ant. 
Frontiers in Zoology, 6: 27. doi:10.1186/1742-9994-6-27

Hebert, P.D.N., Penton, E.H., Burns, J.M., Janzen, D.H. \& Hallwachs, W. (2004). Ten species in one: DNA barcoding reveals cryptic species in the Neotropical skipper butterfly Astraptes fulgerator. Proceedings of the National Academy of Sciences USA, 101: 14812-14817. doi:10.1073/ pnas.0406166101

Heinze, J., Hölldobler, B. \& Yamauchi, K. (1998). Male competition in Cardiocondyla ants. Behavioral Ecology Sociobiology, 42: 239-246.

Heinze, J., Trindl, A., Seifert, B. \& Yamauchi, K. (2005). Evolution of male morphology in the ant genus Cardiocondyla. Molecular Phylogenetics and Evolution, 37: 278-288. doi:10.1016/j.ympev.2005.04.005

Kimura, M. (1980). A simple method for estimating evolutionary rates of base substitutions through comparative studies of nucleotide sequences. Journal of Molecular Evolution, 16: 111-120.

Kinomura, K. \& Yamauchi, K. (1987). Fighting and mating behaviors of dimorphic males in the ant. Journal of Ethology, 5: 75-81.

Kugler, J. (1983). The males of Cardiocondyla Emery (Hymenoptera: Formicidae) with the description of the winged male of Cardiocondyla wroughtonii (Forel). Israeli Journal of Entomology, 17: 1-21.

Lenoir, J.C., Schrempf, A., Lenoir, A., Heinze, J. \& Mercier, J.L. (2007). Genetic structure and reproductive strategy of the ant Cardiocondyla elegans: strictly monogynous nests invaded by unrelated sexuals. Molecular Ecology, 16: 345354. doi:10.1111/j.1365-294X.2006.03156.x

Molbo, D., Machado, C.A., Sevenster, J.G., Keller, L. \& Herre, E.A. (2003). Cryptic species of fig-pollinating wasps: implications for the evolution of the fig-wasp mutualism, sex allocation, and precision of adaptation. Proceedings of the National Academy of Sciences USA, 100: 5867-5872. doi:10.1073/pnas.0930903100

Moreau, C.S., Bell, C.D., Vila, R., Archibald, S.B. \& Pierce, N.E. (2006). Phylogeny of the ants: diversification in the age of angiosperms. Science, 312: 101-104. doi: 10.1126/ science. 1124891

Murray, T.E., Fitzpatrick, U., Brown, M.J.F. \& Paxton, R.J. (2008). Cryptic species diversity in a widespread bumble bee complex revealed using mitochondrial DNA RFLPs. Conservation and Genetics, 9: 653-666. doi:10.1007/s10592007-9394-z

Nylander, J.A.A. (2004). MrModeltest ver. 2. Program distributed by the author. Evolutionary Biology Centre, Uppsala University. (Available from: https:/github.com/ nylander/MrModeltest2)
Oettler, J., Suefuji, M., \& Heinze, J. (2010). The evolution of alternative reproductive tactics in male Cardiocondyla ants. Evolution, 64: 3310-3317. doi:10.1111/j.1558-5646.2010.01090.x

Okita, I., Murase, K., Sato, T., Kato, K., Hosoda, A., Terayama, M., \& Masuko, K. (2013). The spatial distribution of mtDNA and phylogeographic analysis of the ant Cardiocondyla kagutsuchi (Hymenoptera: Formicidae) in Japan. Sociobiology 60: 129-134. doi:10.13102/sociobiology.v60i2.129-134

Ronquist, F., Teslenko, M., van der Mark, P., Ayres, D.L., Darling, A., Höhna, S., Larget, B., Liu, L., Suchard, M.A. \& Huelsenbeck, J.P. (2012). MrBayes 3.2: efficient Bayesian phylogenetic inference and model choice across a large model space. Systematic Biology, 61: 539-542. doi:10.1093/sysbio/ sys029

Ross, K.G., Gotzek, D., Ascunce, M.S. \& Shoemaker, D.D.W . 2010. Species delimitation: a case study in a problematic ant taxon. Systematic Biology, 59: 162-184. doi:10.1093/sysbio/ syp089

Schlick-Steiner, B.C., Steiner, F.M., Moder, K., Seifert, B., Sanetra, M., Dyreson, E., Stauffer, C. \& Christian, E. (2006). A multidisciplinary approach reveals cryptic diversity in Western Palearctic Tetramorium ants (Hymenoptera: Formicidae). Molecular Phylogenetics and Evolution, 40: 259-273. doi:10.1016/j.ympev.2006.03.005

Schrempf, A., Reber, C., Tinaut, A. \& Heinze, J. (2005). Inbreeding and local mate competition in the ant Cardiocondyla batesii. Behavioral Ecology and Sociobiology, 57: 502-510. doi:10.1007/s00265-004-0869-3

Seifert, B. (2003). The ant genus Cardiocondyla (Insecta: Hymenoptera: Formicidae) - a taxonomic revision of the C. elegans, C. bulgarica, C. batesii, C. nuda, C. shuckardi, C. stambuloffii, C. wroughtonii, C. emeryi and C. minutior species groups. Annals of the Natural History Museum Wien, 104(B): 203-338.

Seifert, B. (2008). Cardiocondyla atalanta FOREL, 1915, a cryptic sister species of Cardiocondyla nuda (MAYR, 1866) (Hymenoptera: Formicidae). Myrmecological News, 11: 4348.

Simon, C., Frati, F., Beckenbach, A., Crespi, B., Liu, H. \& Flook, P. (1994). Evolution, weighting, and phylogenetic utility of mitochondrial gene sequences and a compilation of conserved polymerase chain reaction primers. Annals of the Entomological Society of America, 87: 651-701.

Tamura, K., Peterson, D., Peterson, N., Stecher, G., Nei, M. \& Kumar, S. (2011). MEGA5: molecular evolutionary genetics analysis using maximum likelihood, evolutionary distance, and maximum parsimony methods. Molecular Biology and Evolution, 28: 2731-2739. doi:10.1093/molbev/msr121

Terayama, M. (1999). Taxonomic studies of the Japanese Formicidae, part 6. Genus Cardiocondyla Emery. Memoirs of 
the Myrmecological Society of Japan, 1: 99-107.

Thompson, J.D., Higgins, D.G. \& Gibson, T.J. (1994). CLUSTAL W: improving the sensitivity of progressive multiple sequence alignment through sequence weighting, position-specific gap penalties and weight matrix choice. Nucleic Acids Research, 22: 4673-4680.

Yamane, Sk. (2010). Collecting, preparing and identifying ant specimens. In Yamane, Sk., Harada, Y., Eguchi, K. (Eds.), Natural History of Ants in South Kyushu (pp. 170-171). Japan, Nanpo-sinsha, Kagoshima. (In Japanese)

Yamauchi, K. \& Kawase, N. (1992). Pheromonal manipulation of workers by a fighting male to kill his rival males in the ant Cardiocondyla wroughtonii. Naturwissenschaften, 79: 274276.

Yamauchi, K. \& Kinomura, K. (1993). Lethal fighting and reproductive strategy of dimorphic males in Cardiocondyla ants (Hymenoptera: Formicidae). In Inoue, T., Yamane, Sk. (Eds.), Evolution of Insect Societies (pp. 373-402). Hakuhinsya, Tokyo. (In Japanese)

Yamauchi, K., Asano, Y., Lautenschlager, B., Trindl, A. \& Heinze, J. (2005). A new type of male dimorphism with ergatoid and short-winged males in Cardiocondyla cf. kagutsuchi. Insectes Sociaux, 52: 274-281. doi:10.1007/ s00040-005-0803-3

Yamauchi, K., Ishida, Y., Hashim, R. \& Heinze, J. (2007). Queen-queen competition and reproductive skew in a Cardiocondyla ant. Insectes Sociaux, 54: 268-274. doi:10.1007/ s00040-007-0941-x

Yashiro, T., Matsuura, K., Guenard, B., Terayama, M. \& Dunn, R.R. (2010). On the evolution of the species complex Pachycondyla chinensis (Hymenoptera: Formicidae: Ponerinae), including the origin of its invasive form and description of a new species. Zootaxa, 2685: 39-50. 